\title{
Creating Cultural Change: Sex, Safety and Respect Workshops as one Response to Sexual Assault and Harassment on Campus
}

Deanna McCall, Jen Elhindi,

Chris Krogh, Paul Chojenta,

Michelle Lampis and Liam Phelan

University of Newcastle, Australia

\begin{abstract}
In recent years there has been an increase in awareness and calls to action to reduce sexual assault and harassment on university campuses in Australia. This has stemmed from The Australian Human Rights Commission's 2017 report Change the Course: National Report on Sexual Assault and Sexual Harassment at Australian Universities. One response from the University of Newcastle was to adopt an evidence based accredited workshop program called Sex, Safety and Respect. The program was developed by the specialist violence prevention service the Full Stop Foundation. The University commissioned the Foundation to train around 20 professional and academic staff to deliver tailored workshops to students. The workshops seek to address cultural narratives and behaviours that can contribute to sexual violence and offer students an interactive and reflective experience that builds on content delivered in the University's compulsory online consent module. The rollout of the workshops is currently in the early implementation phase and has been supported through engagement with key stakeholders across the University with the aim of creating allies and making this a University-wide approach to effect positive cultural change. In this paper we provide an overview of the implementation process, challenges and successes encountered. Preliminary feedback from staff and students about their experience of the workshops and our plans for expanding the program's reach are also reviewed.
\end{abstract}

\section{Keywords}

Sex and Ethics, University of Newcastle, Australian universities, Full Stop Foundation, Distributed leadership, Ethical bystander

\section{Introduction}

Calls to action to reduce sexual harassment and assault on university campuses have steadily increased in recent years (Harris, Terry \& Ackerman, 2019; Orchowski et al., 2018; Triplett, 2012). As shown in the in 2015 documentary film The Hunting Ground (Dick, 2015), there are significant issues with managing sexual assault and harassment on university campuses in the United States. Interest in The Hunting Ground led to the emergence of the Hunting Ground Australia Project, which held screenings of the documentary across Australian university campuses and encouraged broader conversations about the prevalence of sexual assault and harassment at Australian universities (AHRC, 2017; Carmody et al., 2009; Universities Australia, 2016).

In 2016 Universities Australia, comprising all 39 Australian universities, responded to increasing calls for action with a unified approach and began the Respect. Now. Always. initiative (Universities Australia, 2016). This initiative is a sector-wide program that aims to address concerns about sexual violence on campuses and ways in which to deliver preventative programs. As a first step in this process, Universities Australia engaged the Australian Human Rights Commission to survey 30,000 students nationally to gain an understanding of the prevalence and nature of sexual assault and sexual harassment at Australian universities. 
The findings of the survey highlighted the extent of the problem on Australian university campuses (AHRC, 2017). Around half of all university students $(51 \%)$ reported being sexually harassed on a university campus on at least one occasion in 2016, and $7 \%$ of students reported being sexually assaulted on a university campus on at least one occasion in 2015 or 2016. Women were almost twice as likely to be sexually harassed than men and more than three times more likely to be sexually assaulted. Students identifying as LGBTQIA+ were significantly more likely to be sexually harassed than those who identified as heterosexual, while those identifying as bisexual were more than twice as likely to be sexually assaulted than those who identified as gay, lesbian, homosexual or heterosexual (AHRC, 2017).

The Commission made nine recommendations across five areas of action. One of the action areas is 'changing attitudes and behaviours', which aims to focus on preventative strategies that create cultural change. The Commission recommended implementing education programs that: identify behaviours that constitute sexual assault and sexual harassment; clarify consent and respectful relationships; encourage bystander intervention; target all levels of the organisation; are based on best practice and research; are developed and delivered by individuals and/or organisations with expertise in sexual violence prevention; are developed in consultation with university students, and; include measures for evaluating and refining the actions taken (AHRC, 2017). In response to these recommendations, the University of Newcastle (UON) began implementing several new initiatives. one of which was commissioning the Full Stop Foundation to train University staff to deliver the Foundation's Sex, Safety and Respect program to students.

\section{Theoretical Lenses}

The Sex, Safety and Respect (SSR) program, developed by Carmody, Albury \& Willis (2019), follows Carmody's earlier Sex \& Ethics program for young people (Carmody, 2009). This positively evaluated (see, for example, Carmody 2015) 6-week educational program is consistent with the National Standards for the Primary Prevention of Sexual Assault Through Education (Carmody et al., 2009). The original and the more recent version of the program are grounded in sexual ethics, with a particular focus on Foucault (1981) and his promotion of caring for one's self as being inherently ethical and that caring for others as being an innate part of caring for self (Carmody, 2003). It is through Carmody's adaptation and implementation of Foucault's (1981) conception of ethical sexual subjectivity that behaviour change is incorporated into the workshop via the Sex and Ethics Framework (Carmody, 2009). The framework focusses on each person knowing and caring about themselves, considering the other person, communicating and negotiating their interests and wants, then reflecting both in the moment and following. This framework is introduced early in the program and then applied through the range of activities that follow. The activities allow for critical thinking that challenge pre-existing beliefs that may have supported myths associated with sexual assault, such as victim blaming, as well as experiencing the possibilities of positive bystander interventions.

The SSR program, like the Sex \& Ethics program before it, avoids a normative stance regarding what decisions people should make with regard to sexual behaviour (Carmody 2009; Carmody 2015). Instead, individuals are invited to use the framework to evaluate intimate and/or sexual moments and the way they would choose to act that is right for them and the other person/people involved. This is a departure from programs that provide an explicit or implicit statement about the qualities of 'healthy' relationships. At the same time, clear definitions and legal boundaries regarding sexual assault, harassment, rape, etc are explicitly included. Thus, the openness of decision making is still framed within legal boundaries regarding abuse. 
A critical element of the program is material about being an ethical bystander. Bystanders are individuals not directly involved in, but witnesses to, moments of harassment, harm or abuse. Bystanders are people who have potential to make a difference to those moments through direct or indirect action. Much has been written about the benefits of bystander interventions (Ahmed, 2008; Feldwisch, 2017; Powell, 2010; Inman, Chaudior, Galvinhill \& Sheehy 2018). This approach is supported by Fenton and Mott (2017) who have developed an initiative that aims to encourage participants to become ethical bystanders in order to reduce harm to individuals and enact cultural change on a community level, due to the belief that ethical bystanders have the potential to have a positive impact on cultural change (Fenton \& Mott, 2017).

Another approach that aims to address violence prevention is the ecological model. The ecological model conceptualises violence as a multifaceted phenomenon grounded in an interplay among personal, situational, and sociocultural factors (Heise, 1998). The SSR program takes a relational approach targeting attitudes and behaviours of individuals with the aim of positively influencing their interactions (Carmody, Albury and Willis, 2019). This program sits alongside other UON strategies such as \#NoRoomFor and the compulsory Consent Matters online module that attempt a multi-dimensional approach which allows students to understand sexual harassment and violence and to engage in positive actions in relation to themselves and others.

The fact that SSR is grounded in theory and based on evidence, is socio-culturally relevant to the target audience, utilises multiple teaching methods and is facilitated by trained and accredited staff, means that it meets many of Nation et al.'s (2003) criteria for an Effective Prevention Program. Due to the nature of the program being a one-off intervention the only element of the program that does not meet with Nation et al.'s (2003) criteria is 'sufficient dosage', which requires initiatives to take place over-time. It is for this reason that the program is not the only strategy being utilised by UON to enact cultural change and speaks to the need for other institutions to implement a multifaceted approach that takes place throughout the student lifecycle.

Stepping outside of the workshops to explore the process of implementing a new program, distributed leadership provides a useful theoretical lens for understanding the challenges and opportunities of establishing new initiatives in higher education institutions and has been applied previously in the Australian context (see Carbone et al., 2017). As Spillane et al. (2004, p.27) note, the lens brings attention to the thinking and practice "that emerges in the execution of leadership tasks in and through the interactivity of leaders, followers and situation". That is, while acknowledging those in formal leadership roles in an institution, the lens recognises that initiative can be demonstrated by staff at varying levels of seniority, and in varied role contexts. The theoretical approach is useful for explaining the trajectory to now of UON establishing a program of Sex, Safety and Respect workshops.

\section{Sex, Safety and Respect program}

In 2018 UON commissioned the Full Stop Foundation to train staff facilitators in December of that year. The Full Stop Foundation has an extensive background in working with people who have experienced sexual violence, and this was one of the programs recommended in the Australian Human Rights Commission's review (Carmody \& Ovenden, 2012). The UON wanted to deliver student workshops in-house rather than outsourcing and sought interest from staff to be trained to run workshops. The initial training offered 20 places and invited staff were asked to submit Expressions of Interest. Staff who applied to be trained ranged from Counselling and Student Support team, and Student Living Support, academic staff and other people who worked in related areas. 
Twenty staff attended, with 10 receiving full accreditation, six provisional accreditations, and four not accredited to deliver the program. Accredited trainers are required to undertake ongoing quality assurance, which entails yearly observations to ensure ongoing accreditation of the 2-year licence. At the July workshops discussed below, two of the six provisionally accredited staff had the opportunity to be observed delivering the workshops and subsequently received full accreditation. The UON now has 12 fully accredited staff, comprising four academic staff from faculties, three professional staff from Student Living, four further professional staff from Counselling, and one teacher from the English Language and Foundation Studies Centre.

Once the staff were trained to be facilitators there was then a need to develop an implementation plan. A Working Party was formed to review the training and guide the roll out of the Sex, Safety and Respect (SSR) program in early 2019. The Working Party included stakeholders from Student Central management, and facilitators from the Academic Division, Counselling and Student Living. Two trained staff members agreed to lead the initial roll out of the SSR program under the supervision of the working party and contacted stakeholders and trained facilitators.

Initial attempts at engaging students proved only partially successful, prompting a rethink in approach. One session was promoted to students from the English Language and Foundation Studies Centre but there was minimal sign up from students and the session was cancelled. Another session offered in collaboration with the Newcastle University Postgraduate Student Association (NUPSA) attracted three students only. It was identified that there was a need to develop a student communication campaign and a staff member from student communications agreed to participate in the SSR Working Party and develop material to promote the workshops to students. From this the Working Party decided to take a four-pronged approach (below) to build interest and facilitate recruitment.

1. Raising Sex, Safety and Respect program awareness amongst staff

Running awareness-raising workshops for staff leaders who could also assist with promotion and supporting the roll out on campus. Two SSR workshops were held and a total of 14 staff attended. These sessions were aimed at developing staff awareness of the Sex, Safety and Respect workshops to build awareness of how the workshop had the capacity to address cultural change towards sexual assault and harassment. The intent was for staff to participate and gain a 'hand on [sic]' understanding of the SSR workshop to enable them to recommend to selected students/student cohorts and/or stakeholders across the university.

2. Approach staff leaders in individual faculties

Identified stakeholders were contacted and invited to attend a staff SSR session with the aim of enlisting their assistance with promotion and the roll out on campus. Some staff responded enthusiastically, and dates were booked to roll out sessions to their cohort. This included: Personal Development, Health and Physical Education, Human Services and Social Work. Other faculties have been less responsive but are involved in ongoing conversations.

3. Running a university-wide session

Promoted via the University's Student Communications: this is currently planned for October 2019 and will be an open session for all students.

4. Focussing on students who live in on-campus accommodation 
A Working Group member and Sex, Safety and Respect trainer who works in Student Living identified an opportunity to engage new students through the Semester 2 residency intake during their orientation sessions on 25 July 2019. This approach has, in contrast to earlier efforts, been highly successful. Table 1 below includes workshops, both cancelled and completed, and shows that later efforts were significantly more successful in attracting participants.

Table 1: UON's Sex, Safety and Respect workshops, cancelled and completed, Semester 1, 2019

\begin{tabular}{|l|l|l|l|l|}
\hline Target cohort & \multicolumn{1}{|c|}{ Date } & \multicolumn{1}{|c|}{ Faculty/Unit } & Workshops & \multicolumn{1}{c|}{ Attendees } \\
\hline Enabling Students & Cancelled & $\begin{array}{l}\text { English Language and } \\
\text { Foundation Studies Centre }\end{array}$ & - & - \\
\hline $\begin{array}{l}\text { Bachelor of Science } \\
\text { Students }\end{array}$ & Cancelled & Faculty of Science & - & - \\
\hline Postgraduate Students & $\begin{array}{l}14 \text { March } \\
2019\end{array}$ & $\begin{array}{l}\text { NUPSA (Newcastle University } \\
\text { Postgraduate Students } \\
\text { Association) }\end{array}$ & 1 & 3 \\
\hline $\begin{array}{l}\text { 4th Year Undergrad } \\
\text { Students }\end{array}$ & 3 July 2019 & $\begin{array}{l}\text { Physical Development, Health, } \\
\text { Physical Education }\end{array}$ & 2 & 118 \\
\hline $\begin{array}{l}\text { Intake for Semester 2: } \\
\text { Students living on campus }\end{array}$ & $\begin{array}{l}\text { 25 July } \\
\text { 2019 }\end{array}$ & Student Living & 7 & 50 \\
\hline
\end{tabular}

\section{Sex, Safety and Respect Workshops}

After running some initial workshops, with limited uptake, the Working Party explored the possibility of focussing on students living on-campus as a cohort. With over 1,800 students living in the university's owned and managed residences, it was decided to target new students commencing the contract at the start of Semester 2. On 25 July 2019, a series of seven workshops was held for new students in Student Living across morning and afternoon sessions. Nine facilitators were involved, with one additional facilitator acting as a 'floater' across workshops, available as needed for additional support, and the others all facilitated in pairs. One representative from the Full Stop Foundation was also on site to observe facilitators for accreditation purposes. The following section reports on and analyses participants' and educators' experiences of the seven workshops in aggregate.

The Sex, Safety and Respect workshop is an accredited program which has an embedded evaluation (Appendix 1), which was used to inform the thematic analysis of students' perceptions and an educators' program evaluation form (Appendix 2). There were 10 openended questions of the student evaluation and nine open-ended questions for the educators' program evaluation. At the end of the workshop students were provided with a two-sided evaluation sheet. Students were informed that their participation was voluntary, and that they would not be disadvantaged if they chose not to participate. Educators evaluated the program at the end of the workshop to evaluate their performance and make improvements where necessary. Prior to conducting the workshops ethics clearance was sought from the University's Human Research Ethics Committee. The evaluation was classified as a Quality Assurance Activity.

\section{Evaluation of Sex, Safety and Respect workshops}

The UON mid-year intake of student residents is typically around 250 students, the majority of whom are international students. A total of 118 students attended the workshop, $49 \%$ of the new resident intake for Semester 2. Of those, $104(88 \%)$ were international students $(95$ of whom were study abroad or exchange students) and 14 (12\%) were Australian citizens, with one participant identifying as Indigenous. In addition, 37\% of attendees spoke a language other than English at home. Figure 1 provides an overview of the students' cultural backgrounds. 
The cohort comprised 66 participants (56\%) identifying as female, and 52 participants (44\%) identifying as male. The median age of the mid-year intake was 21 years.

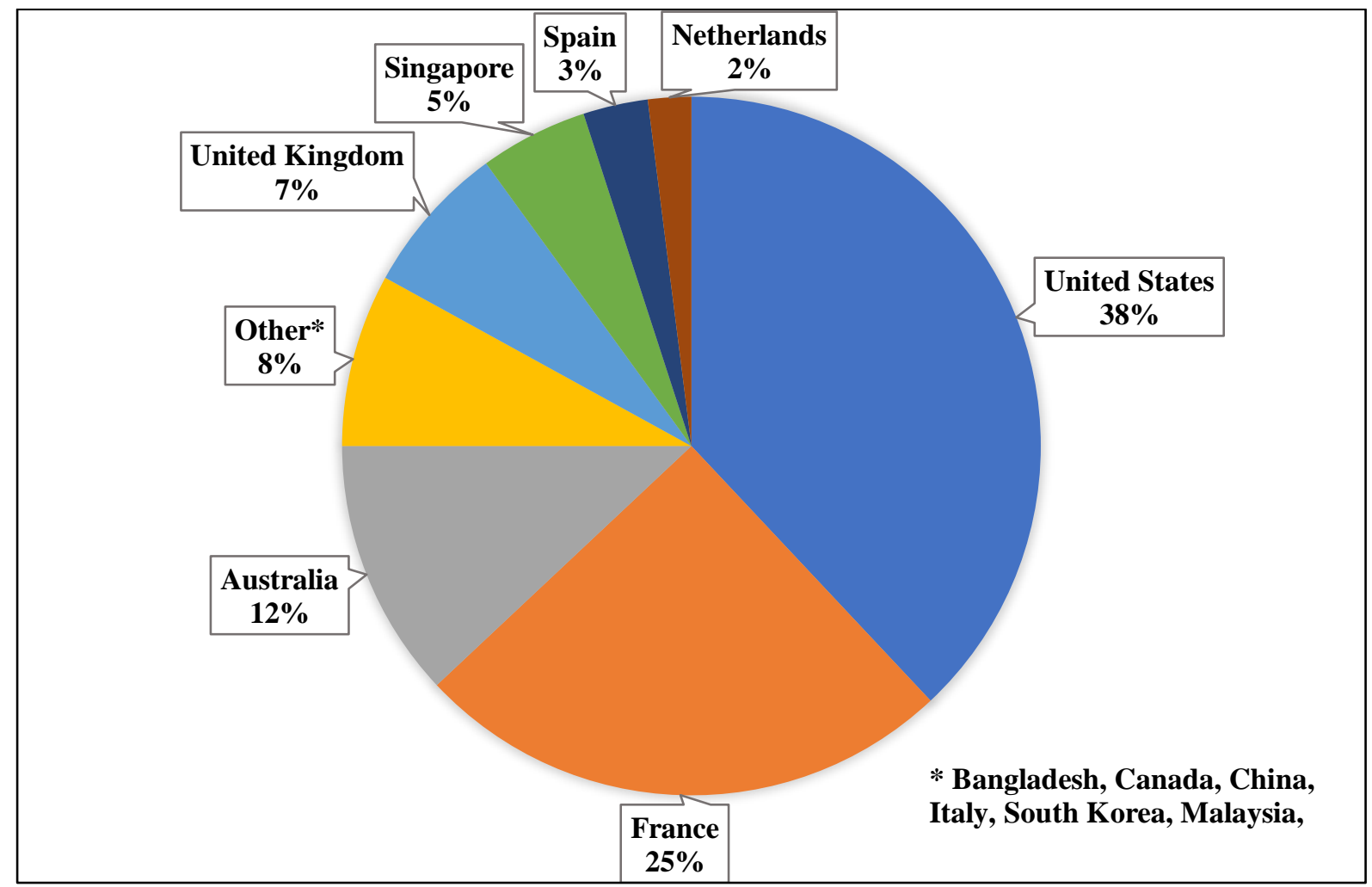

Figure 1: Workshop participants' nationalities

Following the workshops, students and educators were asked to complete the embedded evaluation forms. This process was intended to gain insight into participants' perceptions of the workshop; help evaluate the effectiveness of the workshop; determine what activities were perceived as the most and least beneficial; and to understand if and how students considered the workshop enhanced their knowledge about safe and respectful relationships. A thematic analysis was undertaken of the students and educators' evaluations to generate themes (Braun and Clarke, 2006). The student and staff evaluations were constructed to elucidate the factors that influenced their experience of the Sex, Safety and Respect workshops. These are analysed below.

\section{Students' evaluations}

The student evaluations identified four main elements: the most important thing they learnt; the most challenging aspect of the workshop; how they would describe the workshop to others; and recommendations of areas for improvement. Below is an overview of the main themes.

- The most important thing I learnt...

Participants identified that the Sex and Ethics Framework (44 responses) (Carmody, 2009), ethical bystander content (39) and information regarding New South Wales Laws (31) were the most valuable elements of the workshop. Participants were able to demonstrate an understanding of the Sex and Ethics Framework in that the framework offers steps that they can follow to understand whether they have consent and that overall, the framework was identified as being helpful. One participant stated that the framework helps with: "thinking and doing what is best for me and the other person to enjoy sex and have fun", "a mindset of helping 
us to be safe and have fun and not sex shaming" and "It's ok to put yourself first and take care of yourself."

This indicates that the sex-positive lens through which the workshop is delivered helps participants to understand the content and removes judgement as a barrier to learning. Overall the evaluations indicated that participants considered the workshop to be informative, engaging and relevant, highlighted through descriptions of the workshop: "a great program" that is "useful and needs to be taught everywhere".

\section{- The most challenging thing I learnt...}

Participants identified that they least enjoyed and were most challenged by the role-playing activity (24 responses) of the workshop and that the second most challenging was having to share their thoughts with the group (20). However, almost as many (18) participants indicated that they were not challenged by any aspect of the workshop. Some of the comments highlighted students' discomfort with the role play, as they stated: "being persuaded by 2 people [sic] very intimidating" and "the pressuring activity because I am not normally that type of person".

Other participants also identified that reflecting on their own personal experiences during the workshop was difficult and that the ethical bystander content and the associated scenarios where challenging. Given the nature of the workshop, and the fact that it involves challenging existing beliefs and talking about sex openly, it is unsurprising that participants felt challenged, however as identified by one participant: "being challenged is good".

\section{- How would you describe the workshop to others?}

Participants (40 responses) described the workshops as informative, important and/or necessary (32) and to be interactive and engaging (15). The feedback about the educators was that they created a safe environment and descriptors such as: being friendly, helpful, knowledgeable and non-judgemental. This is illustrated in students' comments, noting that educators were "concerned that we were comfortable (trigger warnings)", and that the workshop was "surprisingly fun and informative", and "less embarrassing than feared".

The evaluation also provided insight into the impact of cultural awareness within the group and their sensitivity to UON's cultural diversity. Stating that they had difficulty: "trying to share my opinion in a way that didn't offend someone (because of my lack of knowledge on their cultures)". While other participants reflected upon their own cultural background stating: "it was very eye opening, especially coming from an Asian country, (conservative) so it is a little eye opening to see these items being addressed so openly", and "a good program. Back in Singapore we did not have sex talk like this. It is something new". However, one participant's insight differed as they stated: "not all cultures find this comfortable". Which serves as a good reminder to educators to be aware of the diversity that exists among participants.

\section{- Recommendations of areas for improvement}

The evaluation form also sought out suggestions from participants for areas of improvement. Responses centred on the physical and comfort-related concerns and some identified that they had already experienced workshops on similar content. The aspect least liked by students was the length of the workshop, expressed in responses such as "worthwhile but time consuming", "tedious but necessary", "important, but repetitive on the things they have herd [sic] before" and a "waste of time".

\section{Facilitators' evaluations}

Five of the nine facilitators completed the Educators program evaluation form, included in the facilitators' manual. The evaluation form (attached at Appendix 2) included questions asking 
facilitators about: the group as a whole, participants' experiences of the workshop, the materials provided to facilitators, their own facilitation, and how they worked with their co-facilitator. The feedback of facilitators centred on three key themes: the positive elements of their experience, opportunities for contextual amendments to materials, and the wider context in which the workshops took place.

\section{- Good, interesting \& fun}

Several themes emerged in facilitators' written comments and were echoed in informal conversations amongst facilitators on the day and at later follow-up meetings. For the most part facilitators found the workshops doable, enjoyable and interesting. Facilitators' responses noted diversity in groups, including quieter and more forthcoming groups: to illustrate, one facilitator reported that "[w]e had a quiet group. They had partied the night before and were clearly tired and possibly hungover." While another indicated that their "group was engaged and willing to take part in all activities".

Another facilitator noted diversity within their group:

The students' seemed to be listening even if they didn't participate actively the whole session. Appeared to be interested in the framework and how to apply but concerned about how to still maintain intimacy in their sexual interactions. The males appeared to want to learn how to be sensitive to sexual consent while the girls seemed more focussed on how to ensure that their relationships were safe and what they wanted.

Facilitators' comments also suggest that with experience, facilitators become more comfortable with the workshops. One facilitator, leading the workshop for the first time since training more than 6 months ago, reported they "took a secondary role in this delivery" while another reported being "happy with my progress as a facilitator. I have now run the workshop three times and am beginning to feel that my delivery is more authentic, rather than being reliant on the manual at all times."

\section{- Opportunities for contextual amendments}

Facilitators noted some possible opportunities for contextual amendments to workshop materials. One example that a number of facilitators noted was the lack of diversity of characters in scenarios in written and video materials. Examples include absences of noncisgendered characters and of non-Anglo characters. This is notable in a university context of long-standing concerted efforts at inclusion, and particularly so with a cohort of largely newly arriving international students. One facilitator noted that "I really think it needs to be more gender and sexually diverse and also [include] discussion around international students and differing cultures that may impact ones [sic] experience and knowledge."

Another noted:

I am still reflecting on the binary vs fluid understandings of gender, and how these are manifest in the manual. I... support the focus on men's violence towards women, and a gender binary approach is important for that. At the same time, I am profoundly struck by how... hetero seemingly all the characters are - in written scenarios, and in the NRL video. And beyond that, how white everyone is ;-). I think I identified only one character's name in a scenario that suggested a non-anglo cultural heritage. I think [this] is probably forgivable first time around, but really does need attention. We work so hard here at uni to be mindful of being inclusive in all sorts of ways - cultural background, indigeneity, gender, etc, etc, etc. 
Another facilitator pointed out that "In our group a student noted that the framework is not appropriate to use in the context of power imbalance and abuse (except to spot when abuse is occurring)." The facilitator went on to suggest that "the manual could be more explicit in how to respond in these situations and to ensure this point is not missed (as I missed it)." This may be a point of particular interest with reference to delivering the Sex Safety and Respect workshops in university contexts, given how hierarchical universities typically are.

\title{
- Wider context
}

Some facilitators extended their evaluation beyond the content of the workshops to wider matters of organisation. As one facilitator said, "It would be good to gain a better understanding of the university's future plans for the workshops." And in the words of another,

\begin{abstract}
I believe in the value of this program and I think it has the potential to have a positive impact on the community. When applied to the students who live on-campus, I think that there are some logistical challenges that make delivery difficult including the need for 2 facilitators to deliver workshop (with a limited number of facilitators available) and the need to keep workshop size at around 20. This is difficult when the ideal time to run workshops with this cohort is the beginning of the contract period (O Week) when a large intake takes place. This challenge will be more evident at the start of 2020 and will require significant planning and problem solving to enable the program to be delivered to these new students at an important time.
\end{abstract}

\section{Discussion}

The evaluation of the Sex, Safety and Respect workshops enabled a clear understanding of the student and staff perception of the benefit of the workshop in addressing sexual assault and harassment on campus. The thematic analysis identified that students had a positive experience and whilst they may have been challenged by some of the activities, it also deepened their knowledge and understanding of the concepts. The feedback indicates that most students left their workshop understanding the key elements of the Sex and Ethics Framework (Carmody, 2009).

Facilitators' reflections are strongly affirming of the workshops. Some facilitators identified opportunities for better contextualising the workshops in university settings already characterised by explicit efforts at inclusion, for example through increased representation of same-sex attracted and gender-diverse characters in workshop materials, along with an increase in representation of people with diverse cultural backgrounds and abilities.

In addition to the delivery and evaluation of the workshops, it is also important to consider the challenge of implementing new programs such as this in university contexts. Some of this challenge is likely a result of UON being the university to engage with the Full Stop Foundation's facilitator training program, and that we are still at a very early stage of engagement. One example illustrates: that greater shared understanding of accreditation requirements would help ensure that more staff could be trained through to accreditation. We now have 12 staff accredited to deliver the training, each available to deliver a small number of workshops each year, and that is very welcome. At the same time, the challenge of cultural change on university campuses is enormous. Greater clarity around the accreditation process, i.e., criteria for accreditation, would be helpful for ensuring a higher accreditation 'strike rate' amongst staff trainees. Continued engagement between UON and the Full Stop Foundation may provide opportunity to fine tune processes of achieving and maintaining accreditation for facilitators. 
Another element that has significantly impacted the roll-out of the workshops was the absence of fully developed strategic planning prior to, or immediately after the training program was completed. To some extent this should be expected, given this is a new program for UON. In response, this resulted in facilitators utilising a distributed leadership (Bolden, Petrov, \& Gosling, 2009; Harris, 2004; Spillane, 2006) framework to implement the program. In this instance, UON's formal leadership framework has supported the initiative through choosing to engage the Full Stop Foundation for staff training, negotiating that relationship, and allocating initial funding for that training in 2018. One staff member has also received approval to allocate 7 hours a fortnight to the Sex, Safety and Respect program. This has in turn created some limited space in which staff in other roles (several part-time), and across UON, have been able to then come together to devise and enact a Sex, Safety and Respect program of works. As demonstrated above, this has included staging some initial, ad hoc workshops in the first half of 2019, and then conducting a major, mid-year program of seven workshops for newly arriving residential students.

\section{Learning for other universities considering implementing similar programs}

- The importance of funding programs that are developed by a sexual assault service, which are developed from an evidence base and delivered through a sex-positive approach.

- A review of the facilitators' training process might also further strengthen the roll out of the Sex, Safety and Respect workshops. This could include greater clarity around the accreditation process and impact on staff in training. Our view is the current approach to assessment is summative in focus, i.e., aimed at certifying, and there is good reason for this. Assessment can also be formative, however, i.e., aimed at supporting learning, and integrated into learning experiences. A more nuanced approach again to trainee assessment could consider lifelong learning (Phelan, 2012), consistent with the ambition of the workshops themselves to contribute to sustained cultural change.

- Ensure that staff are aware of the commitment to the delivery of the workshops, prior to becoming trainers.

- Develop a strategic plan that considers the restrictions of the program (small-scale workshops with no more than 20 attendees and two facilitators for each workshop) as well as the needs of different stakeholders across the university.

- Consider diversity of trained staff and be sure to include both professional and academic staff from diverse areas across the university.

- The challenges of the on-going accreditation process: maintaining the licence; ongoing funding, and, over time; training new facilitators.

- Allocate a staffing resource to support the implementation of the workshops.

- Consider staff workload demands and how to incorporate facilitation into their ongoing roles and potential impact on their ability to continue to participate in the program.

- Continue engagement with the Full Stop Foundation to deepen our shared understanding of the particular university context, i.e., interest in reflecting more sexual, cultural and accessibility diversity in program materials.

- Look for opportunities to embed the workshop into existing relevant courses, for example where students will be working with young people, along with key groups including on-campus residents along with student clubs and representative bodies. 
- To create an opportunity for cultural change, around sexual ethics, you need to focus on the long-term goal and implement a multifaceted approach to ensure the messages and learnings from the workshops.

\section{Conclusion}

Sexual abuse is a profound social challenge (Hill, 2019). Overall, the shared view among the facilitators that the workshops offer participants an opportunity to engage with workshop participants in a way that is sex-positive, non-judgmental and has the potential to have a significant impact on the lives of individuals and the culture that exists in our learning communities. This is reinforced by the evaluations from workshop participants and the facilitators. The staff that have been accredited by the Full Stop Foundation are committed to the continued implementation of the workshops within identified cohorts (including specific degrees and groups across the university). However, it is vital to acknowledge the challenges that have taken place as part of this process with the aim of allowing other institutions to learn from the experience at UON.

The analysis provided here of the participants' experiences in the Sex, Safety and Respect Workshop strongly affirms the value of the program. Our analysis also suggests at least two areas for possible further inquiry. First, there would be merit in seeking to understand the longer-term changes in participants' understandings of ethical relationships. For the present work we collected data immediately at the conclusion of the workshops. We are interested to know how workshop participants' understanding of ethical relationships might change over time, e.g., at graduation, or later still, and we ask this, keeping in mind that cultural change is a large-scale challenge. Second, changes in understanding are one thing and changes in behaviour are another. The indicators of success, or otherwise, of programs such as these will be marked reductions in rates of sexual assault on university campuses. However, it is important to recognise the complexities associated with reporting sexual assaults within university populations: while it is estimated that only $17 \%$ of sexual assaults in the wider community are reported to police, the reporting rate drops to around $9 \%$ in university settings (AHRC, 2017). Mindful of both the scale of the challenge and the preponderance of underreporting, our goal remains to be campuses free from sexual assault.

\section{Acknowledgements}

Thank you to Professor Liz Burd, Dr Stephanie Brookman and Karen Willis AO for the vision to initiate the partnership between the Full Stop Foundation and the University of Newcastle. 


\section{References}

AHRC (Australian Human Rights Commission). (2017). Change the course: National report on sexual assault and sexual harassment at Australian universities. Sydney: Australian Human Rights Commission. Retrieved from https://www.humanrights.gov.au/sites/default/files/document/publication/AHRC_2017_ChangeTheCo urse_UniversityReport.pdf.

Ahmed, E. (2008). 'Stop it, that's enough': Bystander intervention and its relationship to school connectedness and shame management, Vulnerable Children and Youth Studies, 3(3), 203-213, doi: $10.1080 / 17450120802002548$.

Braun, V. and Clarke, V. (2006). Using thematic analysis in psychology. Qualitative Research in Psychology, 3(2). 77-101.

Bolden, R., Petrov, G., \& Gosling, J. (2009). Distributed leadership in higher education: Rhetoric and reality. Educational Management Administration \& Leadership. 37(2), 257-277. doi:10.1177/1741143208100301.

Carbone A., Evans, J., Ross, B., Drew, S., Phelan, L., Lindsay, K., Cottman, C., Stoney, S. \& Ye, J. (2017). Assessing distributed leadership for learning and teaching quality: A multi-institutional study, Journal of Higher Education Policy and Management. 39(2), 183-196, doi:10.1080/1360080X.2017.1276629.

Carmody, M. (2003). Sexual ethics and violence prevention. Social and Legal Studies. 12(2), 199-216

Carmody, M. (2009). Sex and ethics: Young people and ethical sex. Melbourne, Australia: Palgrave Macmillan.

Carmody, M., Evans, S., Krogh, C., Flood, M., Heenan, M., \& Ovenden, G. (2009). Framing best practice: National standards for the primary prevention of sexual assault through education. National Sexual Assault Prevention Education Project for NASASV. University of Western Sydney, Australia.

Carmody, M. (2015). Sex, ethics and young people. New York: Palgrave Macmillan.

Carmody, M., Albury, K. \& Willis, K. (2019). Sex, safety \& respect training for Australian universities. Full Stop Foundation, Sydney and Hunting Ground Australia Project.

Carmody, M. \& Ovenden, G. (2012). Putting ethical sex into practice: Sexual negotiation, gender and citizenship in the lives of young women and men. Journal of Youth Studies, 16(6), 792-807. doi: 10.1080/13676261.2013.763916.

Dick, K. (2015) The hunting ground [DVD] United States

Feldwisch, R. P. (2017). Safe sisters evaluation: A randomized controlled trial of a bystander intervention program to prevent sexual assault (Doctoral dissertation, Indiana University).

Fenton, R. \& Mott, H. (2017). The bystander approach to violence prevention: Considerations for implementations in Europe. Psychology of Violence; 7(3), 450-458, doi:10.1037/vio0000104.

Foucault, M. (1981). The history of sexuality volume one: An introduction. Penguin.

Full Stop Foundation (2019). Sex, safety \& respect: Training for universities. Retrieved from https://www.fullstopfoundation.org.au/MainMenu/Training-Programs/Sex-Safety-Respect-Trainingfor-universities.

Harris, A. (2004). Teacher leadership and distributed leadership: An exploration of the literature. Leading and Managing. 10(2), 1-9.

Harris, A.J, Terry K. J. and, Ackerman A.R. (2019). Campus sexual assault: Forging an action-focused research agenda. Sex Abuse. 31(3), 263-269.

Heise, L. (1998). Violence against women: An integrated, ecological framework. Center for Health and Gender Equity, Violence Against Women, 4(3), 262-290.

Hill, J. (2019). See what you made me do: Power, control and domestic abuse. Carlton: Black Inc..

Inman, E. M., Chaudoir, S. R., Galvinhill, P. R. and Sheehy, A. M. (2018). The effectiveness of the Bringing in the Bystander ${ }^{\mathrm{TM}}$ Program among first-year students at a religiously affiliated liberal arts college. Journal of Social and Political Psychology, 6(2), 511-525. doi:10.5964/jspp.v6i2.971 
Nation, M., Crusto, C., Wandersman, A., Kumpfer, K., Seybolt, D., Davino, E. and Davino K. (2003). What works in prevention: Principles of effective prevention programs. American Psychologist, 58(6-7), pp. 449-456. doi:10.1037/0003-066X.58.6-7.449.

Orchowski, L. M. Edwards, K. M., Hollander, J. A., Banyard, V.L., Senn, C.Y. and Gidycz, C. A. (2018). Integrating sexual assault resistance, bystander, and men's social norms strategies to prevent sexual violence on college campuses: A call to action. Trauma, Violence, \& Abuse. doi: $10.1177 / 1524838018789153$

Phelan, L. (2102). Assessment is a many splendoured thing: Fostering online community and lifelong learning. European Journal of Open, Distance and E-Learning 15(1) 2012. Retrieved from https://eric.ed.gov/?id=EJ979601.

Powell, A. (2010). Configuring consent: Emerging technologies, unauthorized sexual images and sexual assault. Australian \& New Zealand Journal of Criminology, 43(1), 76-90. https://doi.org/10.1375/acri.43.1.76.

Spillane, J. (2006). Distributed leadership. San Francisco, CA: Jossey-Bass.

Spillane, J.P., Halverson, R. and Diamond, J.B. (2004). Towards a theory of leadership practice: a distributed perspective. Journal of Curriculum Studies, 36(1), 3-34. doi.org/10.1080/0022027032000106726.

Triplett, M. (2012). Sexual assault on college campuses: Seeking the appropriate balance between due process and victim protection. Duke Law Journal, 62(2), 487-527. Retrieved from http://www.jstor.org/stable/23364856.

Universities Australia (2016). Respect. Now. Always. Retrieved from https://www.universitiesaustralia.edu.au/project/respect-now-always/

The authors may be contacted via

deanna.mccall@newcastle.edu.au

\section{Please cite this paper as:}

McCall, D. Elhindi, J., Krogh,C., Chojenta, P., Lampis M \& Phelan, L. (2020). Creating cultural change: Sex, safety and respect workshops as one response to sexual assault and harassment on campus. Journal of the Australian and New Zealand Student Services Association, 28(2), 53-66. doi.org.10.30688/janzssa.2020.05 


\section{Appendices}

\section{Appendix 1: Group evaluations form}

Please take a few minutes to reflect on Understanding Sexual Consent and Preventing Sexual Violence by completing the following sentences:

Question 1: 'The most important thing I learnt today was...'

Question 2. 'The Sex and Ethics framework is...'

Question 3. 'The activities were...'

Question 4. 'The session I got most out of was...'

Question 5. 'I felt challenged when...'

Question 6. 'I did not enjoy...'

Question 7. 'The group leaders were...'

Question 8: 'I wish I had...'

Question 9. 'I would describe this program to my friends as...'

Question 10. Do you have any additional comment about the program?

\section{Appendix 2: Educators' program evaluation form}

This evaluation is designed to help you reflect on the particular group you have just completed in order to assist in educating future groups and running them with your coeducator. We suggest you take some time to complete the evaluation separately, and then use it as a structure for discussion with your co-educator.

How did you feel about the group overall?

Did you feel participants got something out of the program? If so, what?

What changes, if any, do you think are needed to the manual (which sections and activities?)

Were there any particular problems you encountered in this group? If so, how did you handle them?

How do you evaluate your own performance as an educator in running this program?

Are there any changes you would make to your approach next time?

How did you work with your co-educator?

If you feel that changes are needed, have you negotiated how these will be handled when you work together again?

Do you have any other comments or issues? 